\title{
What can flies tell us about zinc homeostasis?
}

\author{
Guiran Xiao ${ }^{1,2}$, Bing Zhou ${ }^{2 *}$ \\ ${ }^{1}$ College of food science and engineering, Hefei University of Technology, Hefei, Anhui, 230009, \\ China \\ ${ }^{2}$ State Key Laboratory of Membrane Biology, School of Life Sciences, Tsinghua University, Beijing \\ 100084, China \\ *Corresponding author. Tel: +86-62795322; Fax: +86-62772253; E-mail: \\ zhoubing@mail.tsinghua.edu.cn.
}

\begin{abstract}
Zinc is an essential micronutrient for all organisms. For multicellular organisms, zinc uptake, storage, distribution and export are tightly regulated at both cellular and organismal levels, to cope with the multiple requirements versus the toxicity of the metal ion. During the past decade, the fruit fly Drosophila melanogaster has become an important model organism for the elucidation of metazoan zinc homeostasis. This review describes our current knowledge of various zinc transporters in Drosophila, with an emphasis on the process of dietary zinc uptake in the fly. We also discuss how Drosophila was used as a model to facilitate our understanding of the role of zinc in neurodegenerative diseases.
\end{abstract}

\section{Keywords}

Drosophila, zinc, homeostasis, gut, neurodegeneration

\section{Introduction}

Zinc plays a catalytic or structural role in many enzymes and numerous proteins, and accordingly, contributes to a variety of fundamental biological processes ${ }^{1-3}$. Zinc dyshomeostasis could lead to various defects in multiple biological progresses. Although intensive study of zinc transporters at the cellular level has been performed in recent decades, their physiological functions on the maintenance of zinc homeostasis at the organismal level is less well characterized.

Our current knowledge of zinc metabolism largely comes from mammalian and microbial research. Questions at the organismal level have to be addressed properly with multi-cellular organisms. In terms of rodents, one limitation so far is that not all zinc transporters in mice have been targeted for mutagenesis and for those that have been targeted, mutations were usually generated ubiquitously rather than tissue-specifically, making it difficult to pinpoint their specific roles in a specific tissue or biological process. Another limit is likely functional redundancies among the zinc transporters, making functional analysis sometimes difficult unless various mutations are combined together, which can be time and financially costly.

As a complement to these approaches, Drosophila has been used fruitfully for 
metal studies. For example, more than 50 years ago copper study in Drosophila was performed $^{4}$. Drosophila also helped elucidate the molecular action of the environmental toxin aluminum ${ }^{5}$. Although studying zinc in Drosophila is a relatively recent event, large strides have already been made. This review mainly summarizes our current understanding of Drosophila zinc homeostasis and its relevance to diseases especially neurodegenerations.

\section{Drosophila melanogaster, a model organism to study zinc homeostasis}

The fruit fly $D$. melanogaster represents one of the most important model organisms in genetics and developmental biology. D. melanogaster is a 2-3 mm long organism which is often found around grapes, rotten bananas and other fruits. Many characteristics including its small size, short life cycle (about 12 days), large amount of offsprings, ease of culturing, and the availability of many mutant strains and techniques make the fruit fly an ideal model for genetic studies. The completion of genome sequencing ${ }^{6,7}$ and generation of a large number of overexpression or RNAi fly lines further facilitate the use of Drosophila in biological research.

Drosophila contains approximately 13600 genes, located in only four chromosomes. It has been shown that about $39 \%$ of human genes have orthologues ${ }^{8}$, and $70 \%$ of human disease causing genes have homologues in the fly ${ }^{9,10}$. The intensive use of Drosophila as a model for developmental and genetic investigations has produced a broad range of genetic and molecular approaches that can be readily adapted for the research of zinc homeostasis.

\section{ZIP and ZnT transporters in Drosophila}

Mammalian zinc transporters largely fall into two conserved families, the ZnT (SLC30) family and the ZIP (SLC39) family. Members of the ZnT family generally function in zinc efflux or sequestration into organelles/vesicles, and those of the ZIP family mediate zinc influx from the extracellular medium or vesicular organelles into the cytoplasm ${ }^{3,11-14}$. As shown in Table 1, seven members of the ZnT family and ten members of the ZIP family are found in the Drosophila proteome, displaying homology to mammalian zinc transporters to potentially control zinc homeostasis in Drosophila. Drosophila zinc transporters are identified in multiple ways and named by different principles due to historical reasons. In order to be unified, they are annotated by CG annotation in this review, and frequently noted by their relevance to mammalian counterparts to facilitate the reading for people outside of the field. All published names for each transporter are presented in Table 1.

\subsection{Expression pattern and subcellular localization}

The endogenous expression pattern or subcellular localization of some zinc transporters have been analyzed in Drosophila, including CG17723, CG3994, CG9428 and CG7816. CG17723, a close homologue of ZnT1, is most prominent in the plasma membrane of midgut constrictions, malpighian tubules and is also found in the testis and salivary glands ${ }^{15}$. CG3994, similar to a set of intracellular ZnTs such as $\mathrm{ZnT} 2,3$ or 8 at the amino acid level, is surprisingly found on the plasma membrane of 
malpighian tubules ${ }^{16}$. CG9428, similar to ZIP1, 2 and 3, mainly expresses in the midgut, and is also present in the trachea and testis; it is also located on the plasma membrane ${ }^{14}$. CG7816, or dZIP13, is an intracellular iron transporter located on the secretary pathway, but its tissue and developmental expression patterns have not been characterized in detail ${ }^{17}$. Unavailability of antibodies for the other zinc transporters at present limits a direct characterization of their expression patterns and subcellular localizations.

A fusion of Drosophila ZIP and ZnT with the enhanced green fluorescent protein (eGFP), combined with by overexpression in the larval salivary glands, has allowed a fast test of the intracellular localizations of many zinc transporters ${ }^{18}$. Among these transporters, only CG17723, CG6817 and CG9428 were found to locate on the plasma membrane, CG11163 and CG10449 solely intracellular, and all the others were both on the plasma membrane and intracellular ${ }^{18}$. This study provides some valuable information for the study of Drosophila zinc transporters, but not without caveats. Protein fusion and overexpresion could result in mislocalizations. In addition, different localizations of the same protein may occur in different tissues.

At the RNA level, the expression pattern of most genes could be found in some public Drosophila gene expression databases such as the Berkeley Drosophila Gene Expression Pattern Database (BDGP) ${ }^{19,20}$ and the FlyAtlas Expression Data ${ }^{21} 22$. We have summarized the RNA expression data of other zinc transporters not mentioned above in table 1 according to BDGP and FlyAtlas.

\subsection{Natural mutants of zinc transporters in Drosophila}

Functions of genes can best be revealed by their loss-of-function mutations. Interestingly there are two natural mutants due to zinc transporter mutations. Both of them display remarkable phenotypes.

\section{a) fear of intimacy (foi)}

Drosophila foi (encoded by CG6817) is a ZIP family member initially identified in a large-scale screen for mutations affecting gonad formation in Drosophila ${ }^{23}$, and later found also required for the formation of the tracheal branch fusion during tracheal development ${ }^{24,25}$. foi mutant embryos fail to form the characteristic round shape gonads that are composed of intimately associated germ cells, instead, these cells remain only loosely aligned in a line $\mathrm{e}^{23,25}$. foi mutants die at the end of embryogenesis with obvious abnormalities in the developing tracheal system, but no general defects were observed in a variety of other tissues analyzed including the nervous system, midgut, musculature and embryonic cuticle. The tracheal defect of foi may underlie the lethality of foi mutant.

The protein encoded by foi is localized to the cell plasma membrane and the closest human homologues of FOI may be hZIP6 and hZIP10. When expressed in both yeast and mammalian cells, FOI functions as a zinc transporter ${ }^{24,25}$. Zinc transport activity of foi is essential for the expression of the hemophilic cell-adhesion molecule Drosophila E-cadherin (DE-cadherin), by regulating the accumulation of DE-cadherin in the gonad at the post-transcriptional level. This process is essential for proper 
gonad morphogenesis ${ }^{26}$.

b) Catecholamines up (Catsup)

Catsup (encoded by CG10449) is another ZIP family member essential for development in Drosophila. Catsup was first identified as a negative regulator of tyrosine hydroxylase ( $\mathrm{TH}$, the rate-limiting enzyme for dopamine biosynthesis) activity in D. melanogaster ${ }^{27}$. Elevated TH activity due to Catsup mutations leads to abnormally high levels of catecholamines, resulting in a set of defects such as incomplete cuticle formation, melanotic pseudotumors, female sterility, tracheal development abnormality and lethality ${ }^{27,28}$. Besides, the mutations are dominantly neuroprotective against paraquat exposure likely because of the elevated dopamine level ${ }^{29}$. The exact mechanism for the negative regulation of TH activity by Catsup remains unelucidated yet. Janis M. O'Donnell's lab reported that Catsup physically associates with TH and GTPCH (the rate-limiting enzyme for the biosynthesis of tetrahydrobiopterin ( $\mathrm{BH} 4$, a cofactor of $\mathrm{TH}$ ) and proposed this interaction may negatively regulate their activities, and simultaneously functions in the regulation of synaptic vesicle loading and release of dopamine ${ }^{29,30}$.

Phylogenetic analysis indicated that the protein encoded by Catsup is a close and likely the sole Drosophila homolog of mammalian ZIP7 ${ }^{25,31,32}$. Catsup mutations lead to abnormal accumulation of membrane proteins in the secretory compartment and is accompanied by induction of the ER stress response and increased levels of apoptosis, revealing Catsup plays a general role in the maintenance of ER/Golgi function and protein trafficking ${ }^{32}$.

\subsection{Phenotypes of other zinc transporters when ubiquitously knocked down}

Given the existence of a plethora of potential zinc importers and exporters in Drosophila, with different temporal and spatial expression specificities, as well as likely different metal affinities and transporting abilities, their roles in zinc homeostasis and other physiological functions may much vary.

Since there are only two known natural mutants of zinc transporters, in order to identify the functions of other zinc transport genes that are important in Drosophila, we performed a small-scale screen with the RNAi lines of 15 of the 17 putative zinc transport genes in Drosophila. Although subtle phenotypes remain to be characterized, some obvious defects due to ubiquitous loss of function of these zinc transporters are summarized here. Their gut-specific functions will be analyzed in a later section under Zinc absorption in Drosophila.

When ubiquitously knocked down, five transporters displayed zinc-dependent phenotypes, indicating important roles played by these zinc transporters in zinc homeostasis. CG17723 (dZnT1), CG5130 or CG9430 knockdown is sensitive on zinc-depleted diet (table 1). CG3994 knockdown exhibited sensitivity to zinc supplement in the food ${ }^{14-16}$. CG6898 knockdown is resistant to high dietary zinc, suggesting a partial redundant function with CG9428 and CG9430 in the dietary zinc absorption in Drosophila (further discuss in later section) ${ }^{33}$. Seven members including CG31860, CG6672, CG8632, CG4334, CG6817 (foi), CG10449 (Catsup) and 
CG7816 appear to be important for development; ubiquitous knockdown of them lead to development arrest at different stages (table 1). Among them only CG4334 knockdown could be rescued by zinc depletion in the food. Surprisingly CG7816 (dZIP13) knockdown could be rescued by iron supplement in the diet, suggesting its involvement in iron metabolism (discussed more later in Dietary zinc absorption in Drosophila) (table 1) ${ }^{17}$.

\section{Transient receptor potential melastatin (TRPM)}

Transient receptor potential (TRP) proteins are a large family of cation channels with a variety of functions ${ }^{34}$, and TRPM is a subfamily of it. The Drosophila genome is reported to encode a single TRPM gene (dTRPM) ${ }^{35,36}$. Padinjat Raghu's group reported that $d T R P M$ deficiency leads to reduced zinc levels and decreased cell size as well as defects in the mitochondrial structure and function, resulting in reduction of larval growth. These defects could be rescued by zinc supplementation in the food. They postulated that regulation of $\mathrm{Zn}^{2+}$ homeostasis through dTRPM to a subcellular compartment may be important to mediate class I PI3K-regulated cell growth ${ }^{37}$.

Craig Montell's group reported that dTRPM mutations resulted in shortening of the malpighian tubules and the mutants underwent complete developmental arrest as prepupae; these mutants are, however, sensitive to elevated dietary $\mathrm{Mg}^{2+}$ levels. They found that dTRPM was located on the apical membrane of malpighian tubule cells and dTRPM mutants had increased $\mathrm{Mg}^{2+}$ and decreased $\mathrm{Ca}^{2+}$ in the circulating lymph. They concluded that dTRPM participates in $\mathrm{Mg}^{2+}$ removal from the hemolymph via the malpighian tubules ${ }^{38}$.

How to interpret these seemingly conflicting findings? One possibility is that dTRPM could regulate both $\mathrm{Mg}^{2+}$ and $\mathrm{Zn}^{2+}$ homeostasis; alternatively, it could regulate one cation's homeostasis, which indirectly affects the other's; variations of metal levels in different genetic backgrounds could also contribute to some of the observations made. In terms of genetic background and zinc levels, it is worthwhile to note that Fanis Missirlis's group reported a recessive X-linked mutation which could cause a threefold reduction of body zinc in Drosophila ${ }^{39}$. The identity of this gene, however, still remains a mystery.

\section{Zinc absorption in Drosophila}

Research into dietary zinc absorption in Drosophila started just a few years ago. Nevertheless, thanks to the genetic amiability of this powerful model organism, a relative comprehensive picture of zinc absorption in Drosophila has begun to emerge $^{14,15,33,40}$

\subsection{The digestive system of Drosophila}

As shown in figure 1, in Drosphila food firstly passes through the foregut, proventriculus and then gets into the midgut and later the hindgut. Similar to mammalian intestine and stomach, Drosophila midgut is responsible for food digestion and absorption ${ }^{41}$. The middle part of the midgut or the middle midgut consists of copper cell, large flat cell and the iron cell region. The food uptaken is 
acidified in the copper cell and goes ahead to past the large flat cell to be neutralized in the iron cell region, before getting into the posterior midgut. The majority of nutrient absorption is thought to occur in the posterior midgut ${ }^{41}$. Like mammalian large intestines, Drosophila hindguts function in water and ion reabsorption before faecal excretion. The malpighian tubules are the osmoregulatory and detoxifying organs of Drosophila; they are located at the boundary between the midgut and the hindgut, functioning together with the hindgut to regulate fluid and ion balance similar to mammalian kidneys ${ }^{42-45}$.

\subsection{Dietary zinc influx on the apical membrane}

Zinc absorption is performed by zinc uptake from the food at the luminal side through the apical membrane of the gut, the intracellular trafficking of zinc from the apical membrane to the basolateral membrane of the enterocyte, and zinc efflux into circulation for systemic use.

It is reported that mutations in ZIP1, ZIP2, or ZIP3 confer on mice decreased ability to survive under dietary zinc limitation, especially during pregnancy, when zinc requirement is increased ${ }^{46-48}$. However, direct supporting evidence for the involvement of ZIP1, ZIP2, and ZIP3 in mammalian dietary zinc absorption is still lacking. It is generally accepted that in human and mice the major dietary zinc uptake gene is ZIP4 ${ }^{49-51}$, while the relative importance of other ZIPs in dietary zinc absorption are less certain ${ }^{3}$.

We recently identified in Drosophila two functionally overlapping zinc importers of the ZIP family, which reside on the apical membrane of the enterocyte and are required for efficient dietary zinc absorption. These two ZIP proteins, CG9428 and CG9430, are involved in absorbing zinc from the lumen into the enterocyte ${ }^{14}$ (figure 2A).

dZIP1, encoded by CG9428, is the closest homolog of hZIP1 in the fly genome and expresses intensively in the midgut constriction; dZIP2, encoded by CG9430, is a protein very closely related to CG9428 and immediately adjacent to CG9428 in the genomic DNA. Either ubiquitously or gut-specifically knocking CG9430 down results in sensitivity to zinc deficiency, whereas uniformly knocking CG9428 down did not cause significant defects either on normal food or on zinc-depleted food. A double RNAi of CG9428 and CG9430 results in more severe phenotypes than CG9430 knockdown alone; zinc supplementation in food was able to restore these phenotypes. These results suggest that both of them are zinc importers important for dietary zinc absorption. Though partially redundant, it appears that CG9430 is slightly more important than CG9428 or is a more potent zinc transporter when zinc is severely depleted $^{14}$. Knocking down both of them lead to additional sensitivity to zinc deprivation than knocking down either one of them alone, but has minimal effect under normal dietary conditions, suggesting that there might be additional pathways for zinc absorption.

Richard Burke's lab also identified another ZIP family member CG6898, working in concert with CG9428 and CG9430 to ensure optimal zinc absorption (figure 2A). They provided evidences that CG6898 may be acting as a constitutive, low-affinity 
zinc uptake transporter active in the posterior midgut that works together with CG9428 and CG9430 to ensure adequate zinc supply under a range of dietary conditions $^{33}$. Besides these relatively well characterized zinc uptake transporters, some other zinc transporters such as CG10006, may also participate in zinc absorption, but further studies are needed to validate this ${ }^{40}$.

Among all the Drosophila ZIP genes expressed in the gut, only CG9428 and CG9430 were transcriptionally regulated by dietary zinc levels, with their RNA levels negatively correlated to zinc levels. It is noteworthy that zinc transporters may also subject to post-transcriptional controls, a question little addressed. For example, post-transcriptional regulation of CG9428 was detected at the midgut constriction when dietary zinc was limited ${ }^{14}$, and CG6898 could not be forcibly highly expressed in the gut while it was possible to do so in some other tissues ${ }^{33}$.

\subsection{Zinc sequestration and distribution}

The intracellular zinc trafficking routes from the apical membrane to the basolateral membrane of the enterocytes remain poorly characterized. Zinc transporters residing on the membrane of intracellular organelles may act to sequester cytoplasmic zinc into various compartments for secretion, storage or for proteins that require zinc for their activities. In Drosophila, there are several possible intracellular ZnTs namely CG6672, CG31860, CG11163 and CG8632, and two ZIPs CG94283 and CG10449, as suggested by homology comparison analysis with mammalian zinc transporters (table 1). When they were RNA-interfered in the gut, no significant sensitivity to zinc was observed, suggesting they are not significant in dietary zinc absorption ${ }^{14} 40$.

Some of these transporters deserve a little bit more description here. CG31860 is closer to a set of intracellular zinc transporters including ZnT2, 3 and 8. These transporters such as hZnT4 are found to be localized to the endosomal compartment or trans-Golgi network, and may mediate zinc secretion into the blood stream via exocytosis (reviewed $\mathrm{in}^{3}$ ). One homolog in Caenorhabditis elegans, CDF-2, is functional in zinc storage in the gut granules. CG31860 plays an important role in intracellular zinc distribution ${ }^{14,52,53}$. But the vesicle-resident protein encoded by CG31860 plays an insignificant role in the process of dietary zinc absorption, as suggested by the lack of obvious phenotypes when its expression was knocked down $^{14,52,53}$.

CG6672 is the only one Golgi-resident ZnT family member. ZnT7-null mice displayed reduced body zinc levels that cannot be rescued by intravascular zinc injection $^{54}$. Based on studies in Drosophila, CG6672 is responsible for zinc efflux from the cytoplasm into the Golgi, but does not participate in dietary zinc absorption $^{14,53}$, suggesting the whole secretory pathway may not be involved in zinc efflux to the circulation.

The Drosophila genome harbors four metallothionein genes-MtnA, MtnB, MtnC, and $M t n D$. Metallothioneins play an important role in metal detoxification: Drosophila with all four Mtns knockout are sensitive to copper, cadmium and zinc $\operatorname{load}^{55}$. These metals also induce Mtns expression in various regions of the gut. Though it is undisputable that Mtns play an important role in metal homeostasis, their 
involvement in zinc or metal trafficking needs further elucidation and it remains to be seen whether their effects are direct or not.

\subsection{Dietary zinc efflux at the basolateral membrane}

In Drosophila zinc efflux from the enterocytes to the circulation is mediated by a collaborative function of CG17723 ${ }^{15}$ and its close homolog CG5130 ${ }^{14}$ (figure 2A).

CG17723 shares the highest homology with human ZnT1; it is the first zinc transporter identified for zinc absorption in Drosophila. Ubiquitous or gut-specific CG17723 knockdown leads to growth retardation and developmental arrest under zinc deficiency, which could be complemented by human $\mathrm{ZnT}{ }^{15}$. CG17723 resides on the basolateral membrane of the enterocytes in the midgut constriction and is responsible for zinc efflux for systemic supply ${ }^{15}$. CG17723 is strongly regulated in the gut post-transcriptionally ${ }^{14}$.

Another basolateral membrane localized zinc transporter, CG5130, shares with CG17723 26\% identity and 48\% similarity, and also participates in the exit of zinc from enterocytes to circulation ${ }^{14}$. Knocking down both of CG17723 and CG5130 resulted greater sensitivity to zinc deficiency as compared with knocking down either one of them alone ${ }^{14}$.

\section{Zinc homeostasis in the malpighian tubules}

Besides zinc absorption, zinc excretion is an additional way to control body zinc homeostasis. As shown in figure 1, Drosophila melanogaster has two pairs of malpighian tubules, functionally similar to kidneys in mammalians. Malpighian tubules originate from the junction between the midgut and hindgut, with one pair migrating anteriorly and the other pair posteriorly ${ }^{45,56,57}$. They work together to participate in osmoregulatory regulation and detoxification in Drosophila ${ }^{45,57-59}$.

CG3994 is the only presently known member playing a role in zinc excretion in Drosophila (figure 2B). It was reported to localize to the plasma membrane both under normal and elevated zinc concentrations in malpighian tubules. When CG3994 is repressed or overexpressed, the body zinc level is correspondingly increased or decreased; CG3994 mutant flies are sensitive to zinc supplement and overexpression flies are resistant to high zinc levels. Expression of CG3994 is induced when zinc is supplemented in the food ${ }^{14,16}$. CG3994 has putative transcription factor MTF-1 binding sites (or metal regulatory elements, MREs), and the transcript of CG3994 was markedly increased when MTF-1 was overexpressed, suggesting that the metal regulation of CG3994 in Drosophila is mediated by MTF- $1^{16}$.

Besides the specific expression of CG17723 in the larval midgut constriction for dietary zinc absorption, CG17723 was also found in the malpighian tubules ${ }^{15}$ (figure 2B). Given the basolateral membrane localization of CG17723 in the malpighian tubules, we conjectured that it might be related to renal reabsorption of zinc there. Interestingly, a similar expression orientation of ZnT1 was also found in rodent kidneys ${ }^{60}$.

These two zinc transporters are both zinc exporters. Theoretically a Drosophila zinc importer, which resides on the basal membrane of the malpighian tubules and is 
required for zinc uptake into the malpighian tubules for excretion should exist (figure 2B). Identification of this transporter therefore would fulfill the missing link, i.e., zinc uptake from the body fluid in the malpighian tubule cells.

Interestingly, zinc levels in the malpighian tubules are related to a process of mineralization that could eventually lead to the stone formation. As shown in table 1, three ZnT transporters (CG3994, CG11163, and CG17723) are highly expressed in the malpighian tubules, implying a possible role in regulating tubule zinc homeostasis. Ubiquitously knocking-down these genes significantly reduced kidney stone formation in a fly calcification model generated by inhibiting xanthine dehydrogenase $(\mathrm{Xdh})^{61}$. Dietary and pharmacologic modulation of zinc levels also altered Drosophila stone formation ${ }^{61}$. This suggests that these three transporters are directly or indirectly connected to the tubule zinc homeostasis, and zinc levels in the malpighian tubules are important to this physiologic process.

\section{Zinc and neurodegenerations}

Zinc dyshomeostasis may be connected to many diseases. Accumulation of metals, including zinc, is often found in pathologically affected regions of many neurodegenerative diseases such as Alzheimer's disease (AD), Parkinson's disease (PD), Huntington disease (HD) and so on ${ }^{62,63}$. However, to a large extent, roles of metal ions in these diseases are not well established.

Drosophila has a sophisticated nervous system responsible for behaviors from simple avoidance to learning and memory; its compound eyes allow convenient phenotypic characterization. Many neurodegenerative diseases have been successfully modeled in Drosophila. Expression of human A $\beta 42$ in Drosophila eyes results in a degeneration of eye structures progressing with age ${ }^{64}$. Walter Schaffner's lab found dietary supplementation of zinc or copper ions could exacerbate the eye damage ; consistently, zinc/copper chelators, or over-expression of metal-responsive transcription factor 1 (MTF-1, a zinc-finger protein, a transcription factor with a key role in metal homeostasis and detoxification) or with human or Drosophila metallothionein transgenes alleviated the phenotype ${ }^{64}$. Expression of human A $\beta 42$ in Drosophila brains recapitulates some major AD-like symptoms ${ }^{65,66}$. Using this model, we found that genetic manipulation of the expression of certain zinc importers altered an array of phenotypes associated with $A \beta 42$ expression, including brain vacuolization, locomotor defects and reduced lifespan. Furthermore, we showed that zinc accumulation promotes both the SDS-soluble form and fibril deposits of A $\beta 42$ formation in Drosophila brains ${ }^{67}$.

Mutations in the Drosophila ortholog of human Parkin lead to a series of defects mimicking human Parkinson's disease. MTF-1 mutation enhanced the phenotypes caused by Parkin loss-of-function; elevated expression of Drosophila or human MTF-1 or metallothionein improved the condition of Parkin mutants ${ }^{68}$.

Insoluble aggregates of the microtubule-associated protein Tau are a common feature of several types of neurodegenerative diseases (including AD) collectively termed 'tauopathy". Expression of wild-type or mutant human Tau in the Drosophila 
nervous system caused degenerations ${ }^{69,70}$. In a Drosophila tauopathy model built upon the heterologous expression of hTauR406W (a mutant Tau found in some FTDP-17 patients), we found that zinc reduction and increase, either through genetic or dietary modulation, could respectively alleviate and exacerbate the Tau toxicities. Zinc's involvement in Tau toxicities mainly arises from its direct binding to Tau protein; mutation of the zinc binding sites in Tau greatly suppresses Tau toxicity and astonishingly, the toxicity is no longer affected by zinc level modulations. These studies provided new insights into zinc's exact roles in relevant neurodegenerative diseases, and could even have therapeutic implications.

\section{Conclusive remarks}

In the Drosophila proteome, seven members of the $\mathrm{ZnT}$ family and ten numbers of the ZIP family display homology to mammalian zinc transporters localized to the plasma membrane or intracellular compartments. Our understanding of Drosophila zinc metabolism suggests zinc homeostasis is a conserved evolutionary process; cellular zinc uptake, sequestration, distribution and efflux mechanisms appear rather similar, but not identical, between Drosophila and mammals. Drosophila melanogaster could serve as a tractable model to study the function of zinc transporters, and how an array of zinc transporters function in a coordinative manner during different biological processes. The use of Drosophila indeed advanced our understanding of systemic zinc homeostasis and its relevance to human diseases. It is expected that future studies in Drosophila will continue making contributions to our further understanding of zinc homeostasis overall.

\section{Acknowledgements}

The authors apologize to authors whose works are not cited here due to space limitation. We thank financial supports from the National Science Foundation of China (No. 30688001).

\section{References}

1. Vallee, B.L. \& Falchuk, K.H. The biochemical basis of zinc physiology. Physiol Rev 73, 79-118 (1993).

2. MacDonald, R.S. The role of zinc in growth and cell proliferation. J Nutr 130, 1500S-8S (2000).

3. Wang, X. \& Zhou, B. Dietary zinc absorption: A play of Zips and ZnTs in the gut. IUBMB Life 62, 176-82 (2010).

4. Poulson, D.F., Bowen, V.T., Hilse, R.M. \& Rubinson, A.C. The Copper Metabolism of Drosophila. Proc Natl Acad Sci U S A 38, 912-21 (1952).

5. Wu, Z., Du, Y., Xue, H., Wu, Y. \& Zhou, B. Aluminum induces neurodegeneration and its toxicity arises from increased iron accumulation and reactive oxygen species (ROS) production. Neurobiol Aging 33, 199 e1-12 (2012).

6. Rubin, G.M. \& Lewis, E.B. A brief history of Drosophila's contributions to genome research. 
Science 287, 2216-8 (2000).

7. Adams, M.D. et al. The genome sequence of Drosophila melanogaster. Science 287, 2185-95 (2000).

8. Gilbert, D.G. euGenes: a eukaryote genome information system. Nucleic Acids Res 30, 145-8 (2002).

9. Fortini, M.E., Skupski, M.P., Boguski, M.S. \& Hariharan, I.K. A survey of human disease gene counterparts in the Drosophila genome. J Cell Biol 150, F23-30 (2000).

10. Bier, E. Drosophila, the golden bug, emerges as a tool for human genetics. Nat Rev Genet 6, 9-23 (2005).

11. Lichten, L.A. \& Cousins, R.J. Mammalian zinc transporters: nutritional and physiologic regulation. Annu Rev Nutr 29, 153-76 (2009).

12. Eide, D.J. The SLC39 family of metal ion transporters. Pflugers Arch 447, 796-800 (2004).

13. Palmiter, R.D. \& Huang, L. Efflux and compartmentalization of zinc by members of the SLC30 family of solute carriers. Pflugers Arch 447, 744-51 (2004).

14. Qin, Q., Wang, X. \& Zhou, B. Functional studies of Drosophila zinc transporters reveal the mechanism for dietary zinc absorption and regulation. BMC Biol 11, 101 (2013).

15. Wang, X., Wu, Y. \& Zhou, B. Dietary zinc absorption is mediated by ZnT1 in Drosophila melanogaster. FASEB J 23, 2650-61 (2009).

16. Yepiskoposyan, H. et al. Transcriptome response to heavy metal stress in Drosophila reveals a new zinc transporter that confers resistance to zinc. Nucleic Acids Res 34, 4866-77 (2006).

17. Xiao, G., Wan, Z., Fan, Q., Tang, X. \& Zhou, B. The metal transporter ZIP13 supplies iron into the secretory pathway in Drosophila melanogaster. Elife 3, e03191 (2014).

18. Lye, J.C., Richards, C.D., Dechen, K., Warr, C.G. \& Burke, R. In vivo zinc toxicity phenotypes provide a sensitized background that suggests zinc transport activities for most of the Drosophila Zip and ZnT genes. J Biol Inorg Chem 18, 323-32 (2013).

19. Tomancak, P. et al. Systematic determination of patterns of gene expression during Drosophila embryogenesis. Genome Biol 3, RESEARCH0088 (2002).

20. Rubin, G.M. RNA in situ hybridization data during Drosophila embryogenesis

21. Robinson, S.W., Herzyk, P., Dow, J.A. \& Leader, D.P. FlyAtlas: database of gene expression in the tissues of Drosophila melanogaster. Nucleic Acids Res 41, D744-50 (2013).

22. Venkat Chintapalli, J.W.J.D. The Drosophila gene expression atlas.

23. Moore, L.A., Broihier, H.T., Van Doren, M., Lunsford, L.B. \& Lehmann, R. Identification of genes controlling germ cell migration and embryonic gonad formation in Drosophila. Development 125, 667-78 (1998).

24. Mathews, W.R., Wang, F., Eide, D.J. \& Van Doren, M. Drosophila fear of intimacy encodes a Zrt/IRT-like protein (ZIP) family zinc transporter functionally related to mammalian ZIP proteins. J Biol Chem 280, 787-95 (2005).

25. Van Doren, M. et al. fear of intimacy encodes a novel transmembrane protein required for gonad morphogenesis in Drosophila. Development 130, 2355-64 (2003).

26. Mathews, W.R., Ong, D., Milutinovich, A.B. \& Van Doren, M. Zinc transport activity of Fear of Intimacy is essential for proper gonad morphogenesis and DE-cadherin expression. Development 133, 1143-53 (2006).

27. Stathakis, D.G. et al. The catecholamines up (Catsup) protein of Drosophila melanogaster functions as a negative regulator of tyrosine hydroxylase activity. Genetics 153, 361-82 (1999). 
28. Hsouna, A., Lawal, H.O., Izevbaye, I., Hsu, T. \& O'Donnell, J.M. Drosophila dopamine synthesis pathway genes regulate tracheal morphogenesis. Dev Biol 308, 30-43 (2007).

29. Chaudhuri, A. et al. Interaction of genetic and environmental factors in a Drosophila parkinsonism model. J Neurosci 27, 2457-67 (2007).

30. Wang, Z. et al. Catecholamines up integrates dopamine synthesis and synaptic trafficking. $J$ Neurochem 119, 1294-305 (2011).

31. Huang, L., Kirschke, C.P., Zhang, Y. \& Yu, Y.Y. The ZIP7 gene (Slc39a7) encodes a zinc transporter involved in zinc homeostasis of the Golgi apparatus. J Biol Chem 280, 15456-63 (2005).

32. Groth, C., Sasamura, T., Khanna, M.R., Whitley, M. \& Fortini, M.E. Protein trafficking abnormalities in Drosophila tissues with impaired activity of the ZIP7 zinc transporter Catsup. Development 140, 3018-27 (2013).

33. Richards, C.D., Warr, C.G. \& Burke, R. A role for dZIP89B in Drosophila dietary zinc uptake reveals additional complexity in the zinc absorption process. Int J Biochem Cell Biol 69, 11-9 (2015).

34. Gees, M., Owsianik, G., Nilius, B. \& Voets, T. TRP channels. Compr Physiol 2, 563-608 (2012).

35. Montell, C. The venerable inveterate invertebrate TRP channels. Cell Calcium 33, 409-17 (2003).

36. Padinjat, R. \& Andrews, S. TRP channels at a glance. J Cell Sci 117, 5707-9 (2004).

37. Georgiev, P. et al. TRPM channels mediate zinc homeostasis and cellular growth during Drosophila larval development. Cell Metab 12, 386-97 (2010).

38. Hofmann, T. et al. Drosophila TRPM channel is essential for the control of extracellular magnesium levels. PLoS One 5, e10519 (2010).

39. Afshar, N., Argunhan, B., Bettedi, L., Szular, J. \& Missirlis, F. A recessive X-linked mutation causes a threefold reduction of total body zinc accumulation in Drosophila melanogaster laboratory strains. FEBS Open Bio 3, 302-4 (2013).

40. Richards, C.D. \& Burke, R. Local and systemic effects of targeted zinc redistribution in Drosophila neuronal and gastrointestinal tissues. BioMetals 28, 967-74 (2015).

41. Dubreuil, R.R. Copper cells and stomach acid secretion in the Drosophila midgut. Int J Biochem Cell Biol 36, 745-52 (2004).

42. Gautam, N.K., Verma, P. \& Tapadia, M.G. Ecdysone regulates morphogenesis and function of Malpighian tubules in Drosophila melanogaster through EcR-B2 isoform. Dev Biol 398, 163-76 (2015).

43. Dow, J.A. et al. The malpighian tubules of Drosophila melanogaster: a novel phenotype for studies of fluid secretion and its control. J Exp Biol 197, 421-8 (1994).

44. O'Donnell, M.J., Dow, J.A., Huesmann, G.R., Tublitz, N.J. \& Maddrell, S.H. Separate control of anion and cation transport in malpighian tubules of Drosophila Melanogaster. J Exp Biol 199, 1163-75 (1996).

45. Beyenbach, K.W., Skaer, H. \& Dow, J.A. The developmental, molecular, and transport biology of Malpighian tubules. Annu Rev Entomol 55, 351-74 (2010).

46. Dufner-Beattie, J., Huang, Z.L., Geiser, J., Xu, W. \& Andrews, G.K. Generation and characterization of mice lacking the zinc uptake transporter ZIP3. Mol Cell Biol 25, 5607-15 (2005).

47. Dufner-Beattie, J., Huang, Z.L., Geiser, J., Xu, W. \& Andrews, G.K. Mouse ZIP1 and ZIP3 
genes together are essential for adaptation to dietary zinc deficiency during pregnancy. Genesis 44, 239-51 (2006).

48. Peters, J.L. et al. Targeting of the mouse Slc39a2 (Zip2) gene reveals highly cell-specific patterns of expression, and unique functions in zinc, iron, and calcium homeostasis. Genesis $\mathbf{4 5}$, 339-52 (2007).

49. Dufner-Beattie, J. et al. The acrodermatitis enteropathica gene ZIP4 encodes a tissue-specific, zinc-regulated zinc transporter in mice. J Biol Chem 278, 33474-81 (2003).

50. Wang, K., Zhou, B., Kuo, Y.M., Zemansky, J. \& Gitschier, J. A novel member of a zinc transporter family is defective in acrodermatitis enteropathica. Am J Hum Genet 71, 66-73 (2002).

51. Kury, S. et al. Identification of SLC39A4, a gene involved in acrodermatitis enteropathica. Nat Genet 31, 239-40 (2002).

52. Lye, J.C. et al. Systematic functional characterization of putative zinc transport genes and identification of zinc toxicosis phenotypes in Drosophila melanogaster. J Exp Biol 215, 3254-65 (2012).

53. Dechen, K., Richards, C.D., Lye, J.C., Hwang, J.E. \& Burke, R. Compartmentalized zinc deficiency and toxicities caused by ZnT and Zip gene over expression result in specific phenotypes in Drosophila. Int J Biochem Cell Biol 60, 23-33 (2015).

54. Huang, L., Yu, Y.Y., Kirschke, C.P., Gertz, E.R. \& Lloyd, K.K. Znt7 (Slc30a7)-deficient mice display reduced body zinc status and body fat accumulation. J Biol Chem 282, 37053-63 (2007).

55. Egli, D. et al. A family knockout of all four Drosophila metallothioneins reveals a central role in copper homeostasis and detoxification. Mol Cell Biol 26, 2286-96 (2006).

56. O'Donnell, M.J. \& Maddrell, S.H. Fluid reabsorption and ion transport by the lower Malpighian tubules of adult female Drosophila. J Exp Biol 198, 1647-53 (1995).

57. Dube, K., McDonald, D.G. \& O'Donnell, M.J. Calcium transport by isolated anterior and posterior Malpighian tubules of Drosophila melanogaster: roles of sequestration and secretion. J Insect Physiol 46, 1449-1460 (2000).

58. Linton, S.M. \& O'Donnell, M.J. Contributions of $\mathrm{K}+\mathrm{Cl}-$ cotransport and $\mathrm{Na}+\mathrm{K}+-\mathrm{ATPase}$ to basolateral ion transport in malpighian tubules of Drosophila melanogaster. J Exp Biol 202, 1561-70 (1999).

59. Naikkhwah, W. \& O'Donnell, M.J. Salt stress alters fluid and ion transport by Malpighian tubules of Drosophila melanogaster: evidence for phenotypic plasticity. J Exp Biol 214, 3443-54 (2011).

60. Kim, A.H. et al. L-type $\mathrm{Ca}(2+)$ channel-mediated $\mathrm{Zn}(2+)$ toxicity and modulation by $\mathrm{ZnT}-1$ in PC12 cells. Brain Res 886, 99-107 (2000).

61. Chi, T. et al. A Drosophila model identifies a critical role for zinc in mineralization for kidney stone disease. PLoS One 10, e0124150 (2015).

62. Perera, W.S. \& Hooper, N.M. Ablation of the metal ion-induced endocytosis of the prion protein by disease-associated mutation of the octarepeat region. Curr Biol 11, 519-23 (2001).

63. Savelieff, M.G., Lee, S., Liu, Y. \& Lim, M.H. Untangling amyloid-beta, tau, and metals in Alzheimer's disease. ACS Chem Biol 8, 856-65 (2013).

64. Hua, H. et al. Toxicity of Alzheimer's disease-associated Abeta peptide is ameliorated in a Drosophila model by tight control of zinc and copper availability. Biol Chem 392, 919-26 (2011). 
65. Iijima, K. et al. Dissecting the pathological effects of human Abeta40 and Abeta42 in Drosophila: a potential model for Alzheimer's disease. Proc Natl Acad Sci U S A 101, 6623-8 (2004).

66. Finelli, A., Kelkar, A., Song, H.J., Yang, H. \& Konsolaki, M. A model for studying Alzheimer's Abeta42-induced toxicity in Drosophila melanogaster. Mol Cell Neurosci 26, 365-75 (2004).

67. Lang, M. et al. Genetic inhibition of solute-linked carrier 39 family transporter 1 ameliorates abeta pathology in a Drosophila model of Alzheimer's disease. PLoS Genet 8, e1002683 (2012).

68. Saini, N., Georgiev, O. \& Schaffner, W. The parkin mutant phenotype in the fly is largely rescued by metal-responsive transcription factor (MTF-1). Mol Cell Biol 31, 2151-61 (2011).

69. Wittmann, C.W. et al. Tauopathy in Drosophila: neurodegeneration without neurofibrillary tangles. Science 293, 711-4 (2001).

70. Khurana, V. Modeling Tauopathy in the fruit fly Drosophila melanogaster. J Alzheimers Dis $\mathbf{1 5}$, 541-53 (2008).

71. Jones, M.W., de Jonge, M.D., James, S.A. \& Burke, R. Elemental mapping of the entire intact Drosophila gastrointestinal tract. J Biol Inorg Chem 20, 979-87 (2015).

72. Gutierrez, L. et al. Zinc accumulation in heterozygous mutants of fumble, the pantothenate kinase homologue of Drosophila. FEBS Lett 584, 2942-6 (2010).

\section{Figure legends}

Figure 1 The Drosophila larval digestive system. Notable parts are the foregut, proventriculus, gastric caecae, midgut, malpighian tubules and hindgut. The red-boxed regions are the two domains where obvious zinc accumulation is observed. Using synchrotron X-ray fluorescence microscope (XFM), zinc was observed throughout the gastrointestinal tract with an increased accumulation in the crop region of the anterior midgut and the posterior midgut region ${ }^{71}$. Interestingly, elevated levels of dietary zinc lead to a marked increase in ferritin and metallothioneins protein levels in the posterior midgut ${ }^{15,72}$, suggesting a role for the posterior intestine in zinc homeostasis.

Figure 2 Zinc absorption and excretion in Drosophila. (A) A model for dietary zinc absorption in Drosophila enterocytes. Dietary zinc absorption in the enterocytes likely occurs by directly transversing through the cell, and bypassing the intracellular organelles. (B) Zinc homeostasis in the malpighian tubules. For homologs and alternative names of these transporters please see table 1.For example, CG17723 is alternatively named dZnT1 or ZnT63C in different literatures. 


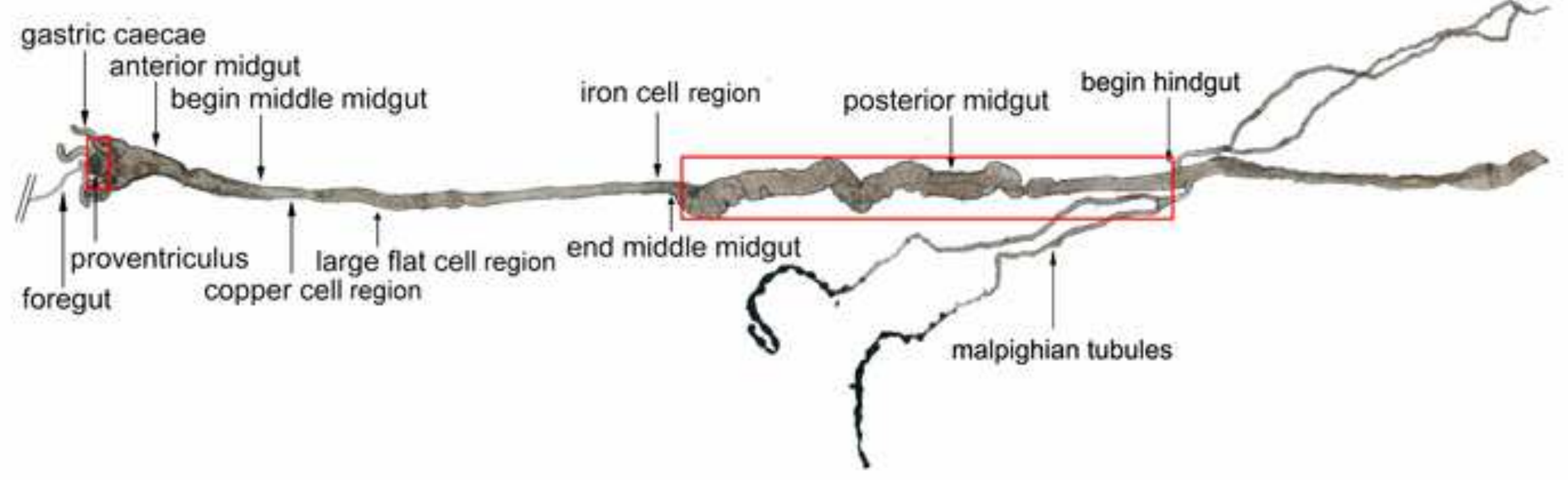


(A)

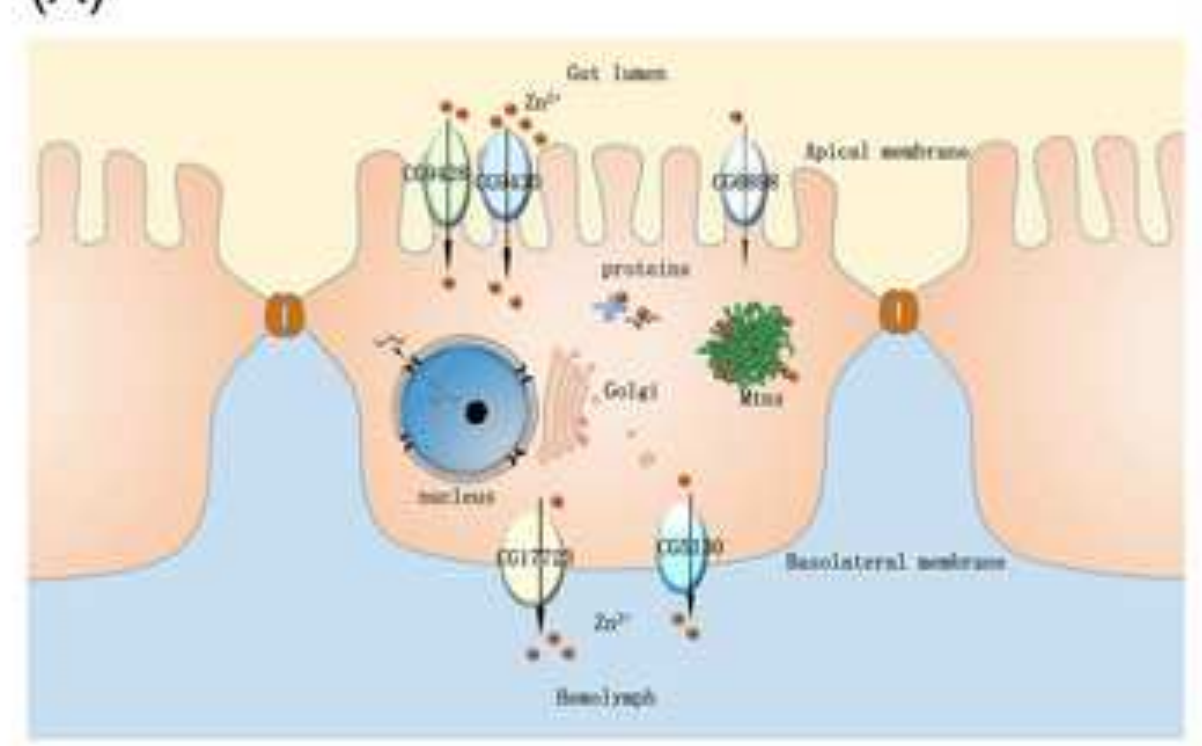

(B)

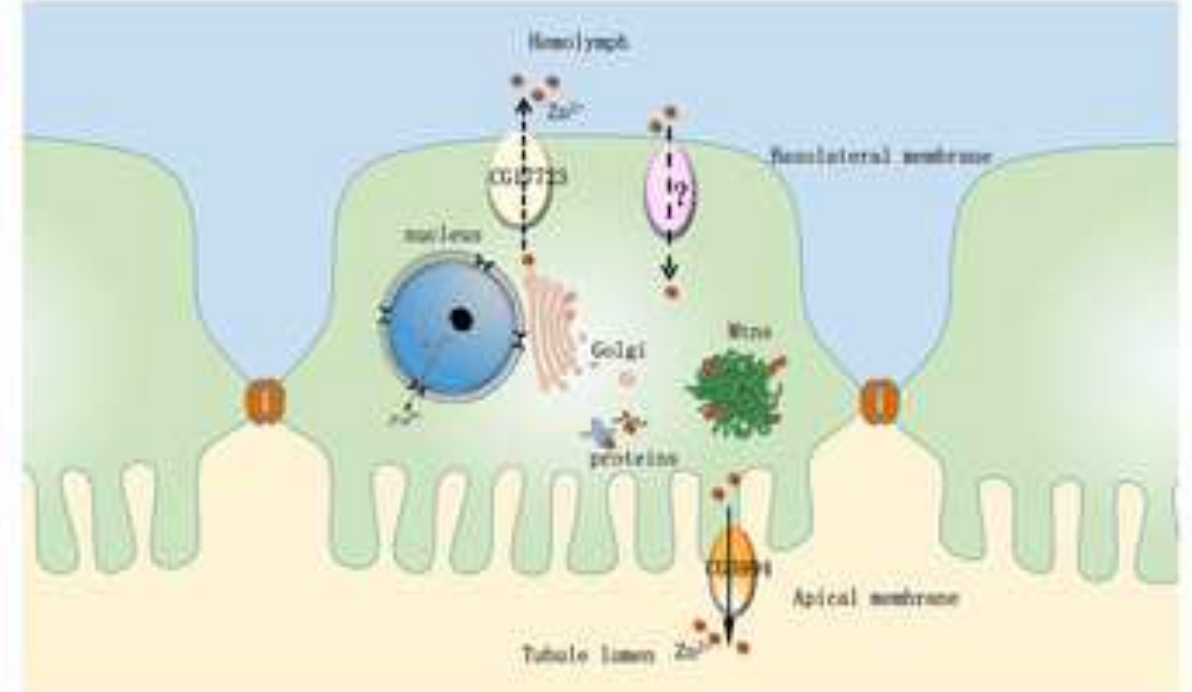


Table1 Drosophila zinc transporters

\begin{tabular}{|c|c|c|c|c|c|c|}
\hline Family & Symbol & $\begin{array}{c}\text { Human } \\
\text { homologs }\end{array}$ & $\begin{array}{l}\text { Subcellular } \\
\text { localization }\end{array}$ & Expression pattern & Function in Drosophila & $\begin{array}{l}\text { Phenotypes of mutation } \\
\text { or ubiquitous RNAi }\end{array}$ \\
\hline \multirow[t]{4}{*}{$\operatorname{SLC} 30 \mathrm{~A}(\mathrm{ZnT})$} & $\begin{array}{l}\text { CG17723 } \\
\text { dZnT1 } \\
\text { dZnT63C }\end{array}$ & $\begin{array}{l}\mathrm{ZnT} 1 \\
\mathrm{ZnT} 10\end{array}$ & plasma membrane $e^{15}$ & $\begin{array}{c}\text { prominent in the midgut } \\
\text { constriction, malpighian tubules } \\
\text { and also found in testis and salivary } \\
\text { glands }^{15}\end{array}$ & $\begin{array}{l}\text { exit of gut zinc to the } \\
\text { circulation }^{15} \text {; facilitating } \\
\text { zinc tubule excretion }\end{array}$ & $\begin{array}{l}\text { sensitive on zinc } \\
\text { depletion food }^{15}\end{array}$ \\
\hline & $\begin{array}{l}\text { CG5130 } \\
\text { dZnT77C }\end{array}$ & $\begin{array}{l}\mathrm{ZnT1} \\
\mathrm{ZnT10}\end{array}$ & $\begin{array}{l}\text { both on the plasma } \\
\text { membrane and } \\
\text { intracellularly }^{18}\end{array}$ & $\begin{array}{l}\text { present in central nervous } \\
\text { (CNS) and tracheal of the embryo } \\
\text { (BDGP), trachea, hindgut, tubule, } \\
\text { midgut and CNS of larvae and male } \\
\text { accessory glands, tubule of the } \\
\text { adults (FlyAtlas) }\end{array}$ & $\begin{array}{l}\text { exit of gut zinc to the } \\
\text { circulation }^{14}\end{array}$ & $\begin{array}{l}\text { sensitive on zinc } \\
\text { depletion food }^{14}\end{array}$ \\
\hline & $\begin{array}{l}\text { CG31860 } \\
\text { dZnT33D }\end{array}$ & $\begin{array}{l}\text { ZnT2 } \\
\text { ZnT3 } \\
\text { ZnT8 }\end{array}$ & $\begin{array}{l}\text { both on the plasma } \\
\text { membrane and } \\
\text { intracellularly }^{18}\end{array}$ & $\begin{array}{l}\text { abundant in testis, also some in } \\
\text { larvae fat body (FlyAtlas) }\end{array}$ & unknown & $\begin{array}{l}\text { lethal at embryo or } 1^{\text {st }} \\
\text { larvae stage, no response } \\
\text { to zinc (unpublished } \\
\text { results) }\end{array}$ \\
\hline & $\begin{array}{l}\text { CG11163 } \\
\text { dZnT41F }\end{array}$ & ZnT4 & solely intracellularly ${ }^{18}$ & $\begin{array}{l}\text { present in brain, hindgut and } \\
\text { midgut of the embryo (BDGP), } \\
\text { head, midgut, hindgut, tubule, } \\
\text { heart, fat body from larval to adults } \\
\text { (FlyAtlas) }\end{array}$ & $\begin{array}{l}\text { facilitating zinc tubule } \\
\text { excretion }^{61}\end{array}$ & $\begin{array}{l}\text { normal, no response to } \\
\text { zinc (unpublished } \\
\text { results) }\end{array}$ \\
\hline
\end{tabular}




\begin{tabular}{|c|c|c|c|c|c|c|}
\hline & $\begin{array}{c}\text { CG6672 } \\
\text { dZnT7 } \\
\text { dZnT86D }\end{array}$ & ZnT7 & $\begin{array}{l}\text { both on the plasma } \\
\text { membrane and } \\
\text { intracellularly }{ }^{18} \text {,mostly } \\
\text { like Golgi }{ }^{14}\end{array}$ & $\begin{array}{l}\text { prominent in larval salivary gland, } \\
\text { midgut, tubule, hindgut, fat body, } \\
\text { trachea, carcass; salivary gland, } \\
\text { midgut, hindgut, fat body and } \\
\text { ovary of adults (FlyAtlas) }\end{array}$ & zinc efflux to the Golgi ${ }^{14}$ & $\begin{array}{c}\text { lethal at } 3^{\text {rd }} \text { larvae stage, } \\
\text { no response to zinc }{ }^{14}\end{array}$ \\
\hline & $\begin{array}{c}\text { CG8632 } \\
\text { dZnT49B }\end{array}$ & ZnT9 & unknown & $\begin{array}{c}\text { present in midgut and gonad of } \\
\text { embryo (BDGP), abundant in adults } \\
\text { brain, head, eye, crop, tubule and } \\
\text { ovary (FlyAtlas) }\end{array}$ & unknown & $\begin{array}{l}\text { lethal at late pupae } \\
\text { stage, no response to } \\
\text { zinc (unpublished } \\
\text { results) }\end{array}$ \\
\hline \multirow[t]{4}{*}{ SLC39A(ZIP) } & $\begin{array}{c}\text { CG9428 } \\
\text { dZIP1 } \\
\text { dZip42C.1 }\end{array}$ & $\begin{array}{l}\text { ZIP1 } \\
\text { ZIP2 } \\
\text { ZIP3 }\end{array}$ & plasma membrane $^{14}$ & $\begin{array}{l}\text { mainly expressed in the midgut, } \\
\text { and is also present in trachea and } \\
\text { testis (FlyAtlas) }\end{array}$ & $\begin{array}{l}\text { absorbing zinc from the } \\
\text { lumen into the enterocyte }\end{array}$ & $\begin{array}{l}\text { normal, no response to } \\
\text { zinc, enhance dZIP2's } \\
\text { phenotype }^{14}\end{array}$ \\
\hline & $\begin{array}{c}\text { CG9430 } \\
\text { dZIP2 } \\
\text { dZip42C.2 }\end{array}$ & $\begin{array}{l}\text { ZIP1 } \\
\text { ZIP2 } \\
\text { ZIP3 }\end{array}$ & $\begin{array}{l}\text { both on the plasma } \\
\text { membrane and } \\
\text { intracellularly }^{14} 18\end{array}$ & $\begin{array}{l}\text { mainly expressed in the midgut, } \\
\text { and is also present in eye, tubule } \\
\text { and fat body (FlyAtlas) }\end{array}$ & $\begin{array}{l}\text { absorbing zinc from the } \\
\text { lumen into the enterocyte }{ }^{14}\end{array}$ & $\begin{array}{l}\text { sensitive on zinc } \\
\text { depletion food }{ }^{14}\end{array}$ \\
\hline & $\begin{array}{l}\text { CG4334 } \\
\text { dZip88E }\end{array}$ & $\begin{array}{l}\text { ZIP1 } \\
\text { ZIP2 } \\
\text { ZIP3 }\end{array}$ & $\begin{array}{l}\text { both on the plasma } \\
\text { membrane and } \\
\text { intracellularly }^{18}\end{array}$ & $\begin{array}{c}\text { highly expressed in larval salivary } \\
\text { gland, also present in tubule and } \\
\text { ovary (FlyAtlas) }\end{array}$ & unknown & $\begin{array}{l}\text { lethal at late pupae stage } \\
\text { or early adult stage, } \\
\text { could be rescued by zinc } \\
\text { depletion in food } \\
\text { (unpublished results) }\end{array}$ \\
\hline & $\begin{array}{l}\text { CG10006 } \\
\text { dZip71B }\end{array}$ & ZIP5 & unknown & $\begin{array}{l}\text { upregulated in tubule, also present } \\
\text { in brain, salivary gland and hind gut } \\
\text { (FlyAtlas) }\end{array}$ & unknown & $\begin{array}{l}\text { normal, no response to } \\
\text { zinc (unpublished } \\
\text { results) }\end{array}$ \\
\hline
\end{tabular}




\begin{tabular}{|c|c|c|c|c|c|}
\hline $\begin{array}{c}\text { CG6817 } \\
\text { foi }\end{array}$ & $\begin{array}{c}\text { ZIP6 } \\
\text { ZIP10 }\end{array}$ & plasma membrane ${ }^{25}$ & $\begin{array}{c}\text { strongly expressed in adults fat } \\
\text { body ovary, and larvae CNS } \\
\text { (FlyAtlas) }\end{array}$ & $\begin{array}{l}\text { required in the mesoderm } \\
\text { for gonad morphogenesis } \\
\text { and tracheal branch fusion } \\
\text { during tracheal } \\
\text { development }\end{array}$ & $\begin{array}{l}\text { lethal at } 3^{\text {rd }} \text { instar larvae } \\
\text { or early pupae stage, no } \\
\text { response to zinc } \\
\text { (unpublished results) }\end{array}$ \\
\hline $\begin{array}{l}\text { CG10449 } \\
\text { catsup }\end{array}$ & ZIP7 & $\mathrm{ER}, \mathrm{Golgi}^{32}$ & $\begin{array}{l}\text { ubiquitous in embryo; expressed in } \\
\text { salivary gland, tubule, trachea, } \\
\text { hindgut, fat body and carcass in } \\
\text { larval; eye, salivary gland, crop, } \\
\text { midgut, tubule, hindgut, heart and } \\
\text { fat body in adults (FlyAtlas) }\end{array}$ & $\begin{array}{c}\text { negative regulator of } \\
\text { tyrosine hydroxylase } \\
\text { activity }^{27}\end{array}$ & $\begin{array}{c}\text { lethal at } 1^{\text {st }} \text { or } 2^{\text {nd }} \text { instar } \\
\text { larvae, no response to } \\
\text { zinc (unpublished } \\
\text { results) }\end{array}$ \\
\hline $\begin{array}{c}\text { CG7816 } \\
\text { dZIP13 } \\
\text { dZip99C }\end{array}$ & ZIP13 & ER, Golgi ${ }^{17}$ & $\begin{array}{c}\text { strongly expressed in midgut, } \\
\text { tubule, heart and testis (FlyAtlas) }\end{array}$ & $\begin{array}{l}\text { supplies iron into the } \\
\text { secretory pathway }{ }^{17}\end{array}$ & $\begin{array}{c}\text { lethal at late pupae stage } \\
\text { or early adult stage, no } \\
\text { response to zinc, could } \\
\text { be rescued by iron } \\
\text { supplementation }^{17}\end{array}$ \\
\hline $\begin{array}{c}\text { CG2177 } \\
\text { dZip102B }\end{array}$ & ZIP9 & unknown & $\begin{array}{l}\text { strongly expressed in tubule, fat } \\
\text { body, crop and thoracicoabdominal } \\
\text { ganglion (FlyAtlas) }\end{array}$ & unknown & \\
\hline $\begin{array}{l}\text { CG13189 } \\
\text { dZip48C }\end{array}$ & ZIP11 & unknown & $\begin{array}{c}\text { strongly expressed in tubule, } \\
\text { hindgut, salivary gland and midgut } \\
\text { (FlyAtlas) }\end{array}$ & unknown & \\
\hline
\end{tabular}

